\title{
Ascophyllum Nodosum, Fucus Vesiculosus and chromium picolinate nutraceutical composition can help to treat type 2 diabetic patients
}

This article was published in the following Dove Press journal:

Diabetes, Metabolic Syndrome and Obesity: Targets and Therapy

\author{
Giuseppe Derosa ${ }^{1-3}$ \\ Maria Divina Pascuzzo 4 \\ Angela D'Angelo', \\ Pamela Maffioli' \\ 'Centre of Diabetes and Metabolic \\ Diseases, Department of Internal \\ Medicine and Therapeutics, University of \\ Pavia and Fondazione IRCCS Policlinico \\ San Matteo, Pavia, Italy; ${ }^{2}$ Laboratory of \\ Molecular Medicine, University of Pavia, \\ Pavia, Italy; ${ }^{3}$ Center for Prevention, \\ Surveillance, Diagnosis and Treatment of \\ Rare Diseases, Fondazione IRCCS \\ Policlinico San Matteo, Pavia, Italy; \\ ${ }^{4}$ Ambulatory Center ASL Torino 4 and \\ ASL Città Di Torino, Torino, Italy
}

\begin{abstract}
Aim: To evaluate the actions of a combination of polifenolic composition (extracted from Ascophyllum Nodosum and Fucus Vesiculosus, InSea $2^{\circledR}$ ) and chromium picolinate compared to placebo in addition to previously taken anti-diabetic therapy in patients with type 2 diabetes.
\end{abstract}

Methods: 175 Caucasian patients with type 2 diabetes were randomized to take nutraceutical combination or placebo for 6 months. One hundred and sixty-four cases completed the study. At baseline and after 6 months, glyco-metabolic control and lipid profile were evaluated.

Results: Glycated hemoglobin was significantly reduced by the nutraceutical combination, but not by placebo, both compared to baseline $(p<0.05)$, and compared to placebo $(p<0.05)$. A similar trend was recorded for fasting plasma glucose (FPG) $[-23.5 \%(p<0.01)$ vs baseline, and $-18.0 \%(p<0.01)$ vs placebo] and post-prandial glucose (PPG) $[-17.1 \%(p<0.01)$ vs baseline, and $-11.1 \%(p<0.05)$ vs placebo]. No variations of lipid profile were recorded compared to baseline, even if it seems to observe a reduction trend of triglycerides level in the nutraceutical group.

Conclusion: In conclusion, a nutraceutical combination of polifenolic composition and chromium picolinate in addition to previously taken anti-diabetic therapy can be helpful in reducing glycated hemoglobin in patients with type 2 diabetes mellitus.

Keywords: Ascophyllum Nodosum, chromium, Fucus Vesiculosus, glycemic control

\section{Introduction}

In patients with type 2 diabetes mellitus, the correlation between cardiovascular complications and hyperglycemia is direct and linear. The impact of cardiovascular events is closely related to the worsening of glycemic control; this association appears even stronger when we consider post-prandial hyperglycemia. ${ }^{1}$ The postprandial plasma glucose, in fact, has been shown to be an independent cardiovascular risk factor and a potent player in the induction of endothelial damage. ${ }^{2,3}$

An adequate lifestyle is the basis to obtain an adequate glycemic control, but to maintain an adequate lifestyle is not simple, especially if patient has a sedentary job. To help patients in following diet, in the latest years nutraceuticals have been marketed. Nutraceuticals include a series of molecules with a favorable effect on glycemia and insulin-resistance. ${ }^{4}$ Among nutraceuticals, a specific polifenolic composition (extracted from Ascophyllum Nodosum and Fucus Vesiculosus in ration 95/5) and chromium picolinate seems to have a positive action on glycemia in dysglycemic
Correspondence: Giuseppe Derosa Department of Internal Medicine and Therapeutics, University of Pavia, and Fondazione IRCCS Policlinico San Matteo P.le C. Golgi, 2, Pavia 27100, Italy

Tel +390382526217

$\mathrm{Fax}+390382526259$

Email giuseppe.derosa@unipv.it 
patients. ${ }^{5}$ The polifenolic composition is composed by florotannins, which act inhibiting $\alpha$-amylase, and $\alpha$-glucosidase with an important hypoglycemic action in vivo. ${ }^{6,7}$ In particular they act on post-prandial hyperglycemia, slowing carbohydrate absorption. At the dose of $250-500 \mathrm{mg}$, this nutraceutical composition induces levels from 25 to 50 times higher in intestinal fluids, compared to inhibiting concentration in vitro. Inhibition happens with a not competitive and reversible mechanism of action on enzymes degrading carbohydrates. ${ }^{6}$ The inhibiting action toward enzymatic activities, reversible and not competitive, seems to reduce, in animal models (rats), glycemia and insulinemia after the administration of amids and glucose.

In literature, a study by Paradise et $\mathrm{al}^{7}$ showed that Ascophyllum Nodosum and Fucus Vesiculosus improve insulin homeostasis in response to carbohydrate ingestion in notdiabetic men and women. On this basis, our study is aimed to evaluate the effects of a combination of polyphenolic composition (extracted from Ascophyllum Nodosum and Fucus Vesiculosus in ration $95 / 5$, InSea $2^{\circledR}$ ), and chromium picolinate (Gdue ${ }^{\circledR}$ marketed by Aesculapius Farmaceutici) compared to placebo in addition to previously taken anti-diabetic therapy in patients with type 2 diabetes mellitus.

\section{Materials and methods}

\section{Study design}

We conducted this multicenter, 6-months, double-blind, randomized, controlled, clinical trial at the Department of Internal Medicine and Therapeutics, University of Pavia (Pavia, Italy) and at Ambulatory Center ASL Torino 4 and ASL Città di Torino (Torino, Italy).

The study protocol was approved by both institutional review boards and was conducted in accordance with the 1994 Declaration of Helsinki, and its amendments and the Code of Good Clinical Practice. ${ }^{8}$ All patients had to provide written informed consent before being enrolled in this study after a full explanation of the procedures had been given.

\section{Patients}

We enrolled 175 Caucasian subjects with type 2 diabetes mellitus, aged $>18$ of either sex (Table 1) according to the ESC (European Society of Cardiology) and EASD (European Association for the Study of Diabetes) Guidelines criteria. ${ }^{9}$ To be enrolled, patients needed to take different anti-diabetic treatments at a stable dose form at least 3 months, with glycated hemoglobin $\left(\mathrm{HbA}_{1 \mathrm{c}}\right)$ level $>6.5 \%$, and in overweight (BMI $\geq 25$ and $<30 \mathrm{Kg} / \mathrm{m}^{2}$ ).
Table I Concomitant diseases and medications during the study

\begin{tabular}{|c|c|c|}
\hline & $\begin{array}{l}\text { Nutraceutical } \\
\text { group }\end{array}$ & $\begin{array}{l}\text { Placebo } \\
\text { group }\end{array}$ \\
\hline $\mathrm{N}$ & 89 & 86 \\
\hline Concomitant disease, $\mathrm{n}(\%)$ & $83(93.3)$ & 81 (94.2) \\
\hline $\begin{array}{l}\text { Hypercholesterolemia } \\
\text { Combined dyslipidemia } \\
\text { Hypertriglyceridemia }\end{array}$ & $\begin{array}{l}53(63.9) \\
26(31.3) \\
4(4.8)\end{array}$ & $\begin{array}{l}59(72.8) \\
20(24.7) \\
2(2.5)\end{array}$ \\
\hline Concurrent medications, $\mathrm{n}(\%)$ & $89(100.0)$ & $86(100.0)$ \\
\hline Statins & $66(74.2)$ & $64(74.4)$ \\
\hline Ezetimibe & II (I2.4) & $8(9.3)$ \\
\hline Fibrates & $12(13.5)$ & $10(11.6)$ \\
\hline Omega-3 & $5(5.6)$ & $4(4.7)$ \\
\hline Hypoglycemic diet only & $3(3.4)$ & $\mathrm{I}(\mathrm{I} . \mathrm{I})$ \\
\hline Metformin & $72(80.9)$ & $76(88.4)$ \\
\hline Sulfonylureas & $15(16.9)$ & $18(20.9)$ \\
\hline Meglitinide derivates & $2(2.2)$ & $3(3.5)$ \\
\hline Pioglitazone & $6(6.7)$ & $4(4.7)$ \\
\hline DPP-4 inhibitors & $13(14.6)$ & $8(9.3)$ \\
\hline GLP-I agonists & $15(16.9)$ & $6(7.0)$ \\
\hline$\alpha$-glucosidase inhibitors & $3(3.4)$ & $2(2.3)$ \\
\hline Insulin & $21(23.6)$ & $18(20.9)$ \\
\hline
\end{tabular}

Note: Data are expressed as $n(\%)$.

Abbreviations: DPP-4, dypeptidil peptidase-4; GLP-I, glucagon like peptide-I.

Patients with previous ketoacidosis or unstable or rapidly progressive diabetic retinopathy, nephropathy or neuropathy were excluded. Impaired hepatic function (defined as plasma aminotransferase and/or gamma-glutamyltransferase level higher than the upper limit of normal [ULN] for age and sex), impaired renal function (defined as serum creatinine level higher than the ULN for age and sex) or severe anemia were considered exclusion criteria. Patients affected by serious cardiovascular disease (CVD) (eg, New York Heart Association class I-IV congestive heart failure or a history of myocardial infarction or stroke) or cerebrovascular conditions within 6 months before study enrolment also were excluded. We did not include pregnant or breastfeeding women or women of childbearing potential not taking adequate contraceptive precautions.

Investigators contacted suitable patients, identified from review of case notes and/or computerized clinic registers, in person or by phone.

\section{Diet and physical activity}

At baseline, all patients were already following an adequate diet, and were encouraged to maintain their usual physical activity. The controlled-energy diet ( $\sim 600 \mathrm{kcal}$ 
daily deficit) followed NCEP-ATP III recommendations. ${ }^{10}$ $50 \%$ of calories derived from carbohydrates, $30 \%$ from fat ( $<7 \%$ saturated, up to $10 \%$ polyunsaturated and up to $20 \%$ monounsaturated) and $20 \%$ from proteins, with a maximum cholesterol content of $300 \mathrm{mg} / \mathrm{d}$, and $35 \mathrm{~g} / \mathrm{d}$ of fiber. Patients were followed by a dietitian and/or specialist physician.

\section{Treatments}

Patients were randomized to take placebo or a nutraceutical agent containing extracted from Ascophyllum Nodosum and Fucus Vesiculosus in a ratio of $95 / 5$ (InSea2 ${ }^{\circledR}$ ) and Chromium Picolinate $\left(\right.$ Gdue $^{\circledR}$ marketed by Aesculapius Farmaceutici: Gdue ${ }^{\circledR}$ is a formulation of InSea $2^{\circledR}$ and chromium) in a 1:1 ratio, for 6 months, in a randomized, doubleblind, placebo-controlled design. Placebo was composed by silicon dioxide, magnesium stearate, dicalcium phosphate and microcrystalline cellulose. Both nutraceutical and placebo were supplied as identical, opaque, tablets in coded bottles to ensure the blind status of the study. Simple randomization was granted using a drawing of envelopes containing randomization codes prepared by a statistician. Medication compliance was assessed by counting the number of pills returned at the time of specified clinic visits. All medications were provided free of charge.

\section{Assessments}

Before starting the study, we collected medical history, physical examination, vital signs (blood pressure and heart rate), a 12-lead electrocardiogram, measurements of height and body weight, calculation of body mass index (BMI), abdominal circumference (Abd. Cir.), assessment of fasting plasma glucose (FPG), post-prandial glucose (PPG), glycated hemoglobin $\left(\mathrm{HbA}_{1 \mathrm{c}}\right)$, lipid profile. Anthropometric and metabolic parameters were evaluated at baseline, and after 6 months.

For a description of how the above parameters were assessed, see our previous study. ${ }^{11}$

\section{Statistical analysis}

A sample of approximately 150 patients was needed to have a power of the study by $80 \%$. The calculation was made by considering a 2-tailed $t$ test for paired data with an alpha error of 5\%. Mean and standard deviation (SD) values were used to summarize quantitative data. We conducted an intention-to-treat (ITT) analysis in patients receiving $\geq 1$ dose of study medication, and the tolerability analysis in patients receiving $\geq 1$ dose of trial medication after randomization. Shapiro-Wilk test was performed for testing the normality of data. The comparison of variables between the two groups was performed with the Student $t$ test for independent data, while paired $t$ test was used to compare values obtained before and after treatment administration. Statistical analysis of data was performed using the Statistical Package for Social Sciences software version 11.0 (SPSS Inc., Chicago, Illinois, USA). Data are presented as mean (SD). ${ }^{12}$ For all statistical analyses, we considered $p<0.05$ as statistically significant.

\section{Results}

One hundred and seventy-five were enrolled in the trial, 89 were randomized to the nutraceutical combination, 86 to placebo; of these, 164 completed the trial. Eleven patients ( 8 in the nutraceutical group and 3 with placebo) did not complete the trial and the reasons for premature withdrawal were lost to follow-up (3 patients), withdrawal of informed consent (5 patients) and not compliant with the treatment ( 3 patients). Concomitant diseases and medications of all the patients are listed in Table 1.

\section{Anthropometric parameters}

No variation of body weight and BMI were recorded; however, a significant reduction of WC was recorded in the nutraceutical group $(p<0.05)$, but not in placebo group, compared to baseline (Tables 2 and 3 ).

\section{Glyco-metabolic control}

Glycated hemoglobin was significantly reduced by the nutraceutical combination, but not by placebo, both compared to baseline $(p<0.05)$ and compared to placebo $(p<0.05)$. A similar trend was recorded for FPG and PPG; both were reduced by the nutraceutical combination compared to baseline $(p<0.01)$ and to placebo $(p<0.01$ for FPG, and $p<0.05$ for PPG) (Tables 2 and 3).

\section{Lipid profile}

No variations of total cholesterol (TC), low-density lipoprotein-cholesterol (LDL-C), high-density lipoprotein-cholesterol (HDL-C) and triglycerides (Tg) were recorded compared to baseline, even if there is a slight, but not significant, reduction of $\mathrm{Tg}$ level in the nutraceutical group (Tables 2 and 3).

\section{Discussion}

De Martin et $\mathrm{al}^{13}$ already reported a reduction of circumferences and blood glucose with this nutraceutical 
Table 2 Anthropometric and glyco-metabolic parameters at baseline and at 6 months after nutraceutical therapy

\begin{tabular}{|c|c|c|}
\hline & \multicolumn{2}{|c|}{ Nutraceutical group } \\
\hline & Baseline & 6 months \\
\hline $\mathrm{N}$ & 89 & 81 \\
\hline $\operatorname{Sex}(M / F)$ & $40 / 49$ & $38 / 43$ \\
\hline Age (years) & $63.9 \pm 10.3$ & $63.4 \pm 10.1$ \\
\hline Weight $(\mathrm{Kg})$ & $101.6 \pm 19.7$ & $99.8 \pm 18.6$ \\
\hline$W C(\mathrm{~cm})$ & $108.3 \pm 10.4$ & $102.7 \pm 9.3^{*}$ \\
\hline BMI $\left(\mathrm{Kg} / \mathrm{m}^{2}\right)$ & $27.3 \pm 2.2$ & $26.9 \pm 1.9$ \\
\hline FPG $(\mathrm{mg} / \mathrm{dL})$ & $152.4 \pm 48.2$ & $116.8 \pm 22.7 * *^{\circ}$ \\
\hline PPG (mg/dL) & $188.3 \pm 56.3$ & $156.2 \pm 32.6 * * \wedge$ \\
\hline $\mathrm{HbA}_{\mathrm{Ic}}(\%)$ & $7.4 \pm 1.6$ & $6.6 \pm 1.2^{* \Lambda}$ \\
\hline $\mathrm{TC}(\mathrm{mg} / \mathrm{dL})$ & $179.6 \pm 20.8$ & $172.8 \pm 18.2$ \\
\hline LDL-C (mg/dL) & $104.1 \pm 10.6$ & $99.1 \pm 9.5$ \\
\hline HDL-C (mg/dL) & $41.5 \pm 6.8$ & $42.6 \pm 7.1$ \\
\hline $\mathrm{Tg}(\mathrm{mg} / \mathrm{dL})$ & $169.8 \pm 51.6$ & $155.7 \pm 42.2$ \\
\hline
\end{tabular}

Notes: Data are expressed as mean \pm standard deviation; ${ }^{*} p<0.05$ vs baseline; ${ }^{* *} p<0.0$ I vs baseline; ${ }^{\wedge} p<0.05$ vs placebo; ${ }^{\circ} p<0.01$ vs placebo.

Abbreviations: WC, waist circumference; BMI, body mass index; FPG, fasting plasma glucose; PPG, post-prandial plasma glucose; $\mathrm{HbA}_{I c}$, glycated hemoglobin; TC, total cholesterol; LDL-C, low-density lipoprotein-cholesterol; HDL-C, highdensity lipoprotein-cholesterol; $\mathrm{Tg}$, triglycerides.

Table 3 Anthropometric and glyco-metabolic parameters at baseline and at 6 months after placebo

\begin{tabular}{|c|c|c|}
\hline & \multicolumn{2}{|c|}{ Placebo group } \\
\hline & Baseline & 6 months \\
\hline $\mathrm{N}$ & 86 & 83 \\
\hline $\operatorname{Sex}(M / F)$ & $45 / 41$ & $43 / 40$ \\
\hline Age (years) & $62.1 \pm 9.7$ & $62.0 \pm 9.5$ \\
\hline Weight (kg) & $100.4 \pm 18.9$ & $97.4 \pm 18.2$ \\
\hline$W C(\mathrm{~cm})$ & $107.5 \pm 10.1$ & $106.7 \pm 9.8$ \\
\hline BMI $\left(\mathrm{kg} / \mathrm{m}^{2}\right)$ & $27.6 \pm 2.4$ & $27.2 \pm 2.1$ \\
\hline FPG $(\mathrm{mg} / \mathrm{dL})$ & $148.7 \pm 37.8$ & $142.4 \pm 35.2$ \\
\hline PPG (mg/dL) & $182.5 \pm 50.3$ & $175.7 \pm 45.8$ \\
\hline $\mathrm{HbA}_{\mathrm{Ic}}(\%)$ & $7.2 \pm 1.5$ & $7.0 \pm 1.3$ \\
\hline TC (mg/dL) & $184.2 \pm 22.5$ & $180.1 \pm 21.9$ \\
\hline LDL-C (mg/dL) & $111.7 \pm 13.5$ & $109.0 \pm 12.1$ \\
\hline $\mathrm{HDL}-\mathrm{C}(\mathrm{mg} / \mathrm{dL})$ & $40.2 \pm 5.9$ & $39.6 \pm 5.7$ \\
\hline $\mathrm{Tg}(\mathrm{mg} / \mathrm{dL})$ & $161.7 \pm 47.8$ & $157.1 \pm 44.3$ \\
\hline
\end{tabular}

Notes: Data are expressed as mean \pm standard deviation; $p$ is not statistically significant.

Abbreviations: WC, waist circumference; $B M I$, body mass index; FPG, fasting plasma glucose; PPG, post-prandial plasma glucose; $\mathrm{HbA}_{\mathrm{Ic}}$, glycated hemoglobin; TC, total cholesterol; LDL-C, low-density lipoprotein-cholesterol; HDL-C, high-density lipoprotein-cholesterol; Tg, triglycerides.

combination, according to our results. The reduction of glycemia observed in our study can be due to the inhibiting action of the polyphenolic composition toward enzymatic activities, in an acarbose-like mechanism. The ability of a phytocomplex obtained from these algae to inhibit both enzymes has already been reported by Roy et al, ${ }^{14}$ and lately by Gabbia et al. ${ }^{15}$ Gabbia showed that the administration of this extract in mice fed with a diet rich in fat is associated with a delay in carbohydrate digestion, but also with a decrease in its assimilation. Furthermore, Ascophyllum Nodosum and Fucus Vesiculosus contain polyunsaturated fatty acids (PUFAs) and the quantity is abundant, ranging from near $44 \%$ to $48 \%$ for the Ascophyllum Nodosum and Fucus Vesiculosus, respectively. ${ }^{16}$ Our group demonstrated that n-3 PUFAs [Eicosapentaenoic acid (EPA) and Docosahexaenoic acid (DHA)] were effective in reducing glycemia in patients affected by impaired fasting plasma glucose or impaired glucose tolerance and seem to be helpful to slow the development of type 2 diabetes mellitus. ${ }^{17}$ Ascophyllum Nodosum and Fucus Vesiculosus contain only EPA represented from near $4 \%$ to $10 \%$ of the total fatty acids, ${ }^{16}$ but, however, it could have contributed to improve glycemic control.

Moreover, also chromium can play a role on glycometabolic improvement. Chromium is an essential trace element involved in the metabolism of carbohydrates, lipids and proteins. The recommended daily intake of chromium is $40 \mu \mathrm{g}$, but diet often does not provide minimum quantities, also because its bioavailability is low, less than $2 \%$. Chromium is a necessary cofactor for many insulin functions, because it promotes the binding to its receptors in the striated muscle cells, adipocytes and hepatocytes and furthermore, promotes the phosphorylation of the receptors. These mechanisms contribute to the transport of glucose in the liver, muscle and adipose tissue to be used for energetic purposes, thereby improving glucose tolerance.

A recent meta-analysis of 15 controlled clinical trials in a total of 1690 patients showed the beneficial effects of integration of chromium in diabetic patients. The studies document that chromium reduces hyperglycemia, corrects insulinemia, reduces the need of oral hypoglycemic agent, reduces $\mathrm{TC}$ and $\mathrm{Tg}$ and allows better control of body weight and fat mass. The authors of the meta-analysis concluded that the analyzed data support the safety and efficacy of chromium and in particular of chromium picolinate in the control of cholesterol and hyperglycemia in type 2 diabetic patients. ${ }^{18}$

A study limitation is that, although the combination therapy showed a significant effect, we still cannot know which of the composition worked. Since the chromium picolinate is widely used in prevention and treatment of type 2 diabetes mellitus with confirmed efficiency, a group 
treated with only polyphenolic extracts or chromium picolinate designed as the single factor control could have been helpful to clarify this point. Another limitation was that the majority of patients were under hypoglycemic drugs, and in particular under metformin; however, background therapy was not changed during the six months trial to avoid bias.

\section{Conclusion}

A nutraceutical combination of polyphenolic composition (extracted from Ascophyllum Nodosum and Fucus Vesiculosus in ration 95/5) and chromium picolinate in addition to previously taken anti-diabetic therapy can be helpful in reducing $\mathrm{HbA}_{1 \mathrm{c}}$ in patients with type 2 diabetes mellitus.

\section{Disclosure}

The authors report no conflicts of interest in this work.

\section{References}

1. Bartnik M, Norhammar A, Rydén L. Hyperglycaemia and cardiovascular disease. $J$ Intern Med. 2007;262:145-156. doi:10.1111/j.13652796.2007.01831.x

2. Derosa G, D'Angelo A, Salvadeo SA, et al. Oral glucose tolerance test effects on endothelial inflammation markers in healthy subjects and diabetic patients. Horm Metab Res. 2010;42:8-13. doi:10.1055/s0029-1237728

3. Derosa G, D'Angelo A, Salvadeo SA, et al. Modification of vascular and inflammation biomarkers after OGTT in overweight healthy and diabetic subjects. Microvasc Res. 2010;79:144-149. doi:10.1016/j. mvr.2010.01.002

4. Derosa G, Maffioli P. Nutraceuticals for the treatment of metabolic diseases: evidence from clinical practice. Expert Rev Endocrinol Metab. 2015;10:297-304. doi:10.1586/17446651.2015.995630

5. Derosa G, Cicero AFG, D’Angelo A, Maffioli P. Ascophyllum nodosum and Fucus vesiculosus on glycemic status and on endothelial damage markers in dysglicemic patients. Phytother Res. 2019;33 (3):791-797. doi:10.1002/ptr.6272

6. Roy MC, Anguenot R, Fillion C, Beaulieu M, Bèrubé C, Richard D. Effect of a commercially-available algal phlorotannins extract on digestive enzymes and carbohydrate absorption in vivo. Food Res Int. 2011;44:3026-3029. doi:10.1016/j.foodres.2011.07.023

7. Paradis ME, Couture P, Lamarche B. A randomised crossover placebocontrolled trial investigating the effect of brown seaweed (Ascophyllum nodosum e Fucus vesiculosus) on postchallenge plasma glucose and insulin levels in men and women. Appl Physiol Nutr Metab. 2011;36:913-919. doi:10.1139/h11-115
8. CIOMS publications. The Council for International Organisation of Medical Sciences. Proposed International Guidelines for Biomedical Research Involving Human Subjects. Geneva; 1982.

9. Rydén L, Standl E, Bartnik M, et al; Task Force on Diabetes and Cardiovascular Diseases of the European Society of Cardiology (ESC); European Association for the Study of Diabetes (EASD). Guidelines on diabetes, pre-diabetes, and cardiovascular diseases: executive summary. The Task Force on Diabetes and Cardiovascular Diseases of the European Society of Cardiology (ESC) and of the European Association for the Study of Diabetes (EASD). Eur Heart J. 28;2007:88-136. doi:10.1093/eurheartj/ ehl260

10. Lichtenstein AH, Appel LJ, Brands M, et al. Summary of American Heart Association Diet and Lifestyle Recommendations Revision 2006. Arterioscler Thromb Vasc Biol. 2006;26:2186-2191. doi:10.1161/01.ATV.0000238352.25222.5e

11. Derosa G, Ragonesi PD, Fogari E, et al. Sitagliptin added to previously taken antidiabetic agents on insulin resistance and lipid profile: a 2-year study evaluation. Fundam Clin Pharmacol. 2014;28(2):221-229. doi:10.1111/fcp.12001

12. Winer BJ. Statistical Principles in Experimental Design. 2nd ed. New York (USA): McGraw-Hill; 1971

13. De Martin S, Gabbia D, Sirianni A, et al. Effect of dietary supplementation with fucus vesiculosus and ascophyllum nodosum (GdueTM) on fasting blood insulin and glucose levels and abdominal circumference: a clinical study. World Congress on November 16-18. Barcelona, Spain: Nutrition and Obesity Prevention Source. Abstract; 2017

14. Roy M, Anguenot R, Fillion C, Beaulieu M, Bérubé J, Richard D. Effect of a commercially-available algal phlorotannins extract on digestive enzymes and carbohydrate absorption in vivo. Food Res Int. 2011;44:3026-3029. doi:10.1016/j.foodres.2011.07.023

15. Gabbia D, Dall'Acqua S, Di Gangi IM, et al. The phytocomplex from fucus vesiculosus and ascophyllum nodosum controls postprandial plasma glucose levels: an in vitro and in vivo study in a mouse model of NASH. Mar Drugs. 2017;15:41. doi:10.3390/ md15020041

16. Lorenzo JM, Agregán R, Munekata PES, et al. Proximate composition and nutritional value of three macroalgae: Ascophyllum nodosum, Fucus vesiculosus and Bifurcaria bifurcata. Mar Drugs. 2017;15:360. doi:10.3390/md15110360

17. Derosa G, Cicero AF, D'Angelo A, Borghi C, Maffioli P. Effects of n-3 pufas on fasting plasma glucose and insulin resistance in patients with impaired fasting glucose or impaired glucose tolerance. Biofactors. 2016;42:316-322. doi:10.1002/biof.1277

18. Broadhurst CL, Domenico P. Clinical studies on chromium picolinate supplementation in diabetes mellitus-a review. Diabetes Technol Ther. 2006;8:677-687. doi:10.1089/dia.2006.8.677

\section{Publish your work in this journal}

Diabetes, Metabolic Syndrome and Obesity: Targets and Therapy is an international, peer-reviewed open-access journal committed to the rapid publication of the latest laboratory and clinical findings in the fields of diabetes, metabolic syndrome and obesity research. Original research, review, case reports, hypothesis formation, expert opinion and commentaries are all considered for publication. The manuscript management system is completely online and includes a very quick and fair peer-review system, which is all easy to use. Visit http://www.dovepress.com/testimonials.php to read real quotes from published authors. 